\title{
Role of Indocyanine Green in Fluorescence Imaging with Near- Infrared Light to Identify Sentinel Lymph Nodes, Lymphatic Vessels and Pathways Prior to Surgery - A Critical Evaluation of Options
}

\section{Die Rolle von Indocyaningrün als Fluoreszenzfarbstoff in Kombination mit Nah-Infrarotlicht in der operativen Medizin zur Sentinellymphknoten-, Gefäß- und Lymphbahndarstellung - eine kritische Beurteilung der Möglichkeiten}

\section{(ㄷ) (i) (우)}

\section{Authors}

Andreas Hackethal ${ }^{1}$, Markus Hirschburger ${ }^{2}$, Sven Oliver Eicker ${ }^{3}$, Thomas Mücke ${ }^{4}$, Christoph Lindner ${ }^{5}$ Olaf Buchweitz $^{1}$

\section{Affiliations}

1 Tagesklinik Altonaer Straße, Frauenklinik an der Elbe, Hamburg, Germany

2 Allgemeinchirurgie, Klinikum Worms gGmbH, Worms, Germany

3 Neurochirurgie, Universitätsklinikum Hamburg-Eppendorf, Hamburg, Germany

4 Mund-Kiefer-Gesichtschirurgie, St. Josefshospital, Krefeld-Uerdingen, Germany

5 Gynäkologie und Geburtshilfe, Agaplesion Diakonieklinikum Hamburg, Hamburg, Germany

Key words

ICG, sentinel, indocyanine green

Schlüsselwörter

ICG, Sentinel, Indocyaningrün

received 24.9.2017

revised 29.11.2017

accepted 30.11.2017

\section{Bibliography}

DOI https://doi.org/10.1055/s-0043-123937

Geburtsh Frauenheilk 2018; 78: 54-62 @ Georg Thieme

Verlag KG Stuttgart · New York | ISSN 0016-5751

Correspondence

Dr. Andreas Hackethal, MD, PhD

Tagesklinik Altonaer Straße

Altonaer Straße 59-61, 20357 Hamburg

Oberbaumbrücke 1, 20457 Hamburg, Germany

hackethal@tka-hh.de

Deutsche Version unter:

https://doi.org/10.1055/s-0043-123937
ABSTRACT

Modern surgical strategies aim to reduce trauma by using functional imaging to improve surgical outcomes. This reviews considers and evaluates the importance of the fluorescent dye indocyanine green (ICG) to visualize lymph nodes, lymphatic pathways and vessels and tissue borders in an interdisciplinary setting. The work is based on a selective search of the literature in PubMed, Scopus, and Google Scholar and the authors' own clinical experience. Because of its simple, radiation-free and uncomplicated application, ICG has become an important clinical indicator in recent years. In oncologic surgery ICG is used extensively to identify sentinel lymph nodes with promising results. In some studies, the detection rates with ICG have been better than the rates obtained with established procedures. When ICG is used for visualization and the quantification of tissue perfusion, it can lead to fewer cases of anastomotic insufficiency or transplant necrosis. The use of ICG for the imaging of organ borders, flap plasty borders and postoperative vascularization has also been scientifically evaluated. Combining the easily applied ICG dye with technical options for intraoperative and interventional visualization has the potential to create new functional imaging procedures which, in future, could expand or even replace existing established surgical techniques, particularly the techniques used for sentinel lymph node and anastomosis imaging.

\section{ZUSAMMENFASSUNG}

Moderne chirurgische Strategien zielen auf Reduktion von Trauma mit Nutzung funktioneller Darstellungsmethoden zur Verbesserung chirurgischer Ergebnisse. Die Relevanz von Indocyaningrün (ICG) als Fluoreszenzfarbstoff, zur Darstellung von Lymphknoten, Lymphbahnen, Gefäßen und Gewebegrenzen, wird in dieser Übersichtsarbeit interdisziplinär dargestellt und kritisch bewertet. Diese Arbeit basiert auf einer selektiven Literaturrecherche in PubMed, Scopus, Google Scholar und 
den klinischen Erfahrungen der Autoren. Aufgrund der einfachen, strahlungsfreien und komplikationsarmen Anwendung hat sich ICG in den letzten Jahren als eine wichtige klinische Indikatorsubstanz etabliert. In der onkologischen Chirurgie wird ICG zur Markierung von Sentinellymphknoten intensiv und mit vielversprechenden Ergebnissen genutzt und zeigt zum Teil verbesserte Detektionsraten im Vergleich mit den etablierten Verfahren. Durch Visualisierung und Quantifizierung von Gewebedurchblutungen kann ICG zu einer Verringerung von Anastomoseinsuffizienzen und Transplantatnek- rosen führen. Die Darstellung von Organgrenzen, Grenzen von Lappenplastiken sowie deren postoperativer Vaskularisierung sind auch Gegenstand der wissenschaftlichen Evaluation. Die Kombination des leicht anwendbaren Farbstoffs ICG mit den technischen Möglichkeiten der intraoperativen und interventionellen Visualisierung hat das Potenzial, neue funktionelle Darstellungen zu ermöglichen und die bisher etablierten operativen Techniken, insbesondere die Sentineltechniken und Anastomosetechniken, zu erweitern und möglicherweise zukünftig abzulösen.

\section{Introduction}

Modern surgical medicine aims to reduce trauma while maintaining the same outcomes or even improving them and is increasingly making use of functional imaging.

Indocyanine green (ICG) is used in innovative surgical techniques, for example to stain organs and tumor tissue, for the intraoperative imaging of flap plasty or bowel anastomosis vascularization and for the detection of sentinel lymph nodes [1 -8].

The use of ICG in medicine has been described since the 1950s [9]. Particularly following recent developments in video endoscopy techniques, the use of ICG in medical practice has expanded to include many different specialties. Scientific and clinical interest in the medical application of indocyanine green (ICG) has greatly increased latterly; PubMed alone lists 1221 publications for the period from January 2016 to August 2017 ( $>$ Fig. 1). In view of the range of medical areas where ICG is used and the promising results, this review aims to describe and critically evaluate the current state-of-the-art in different surgical specialties.

\section{Characterization, metabolization}

ICG is a tricarbocyanine dye which fluoresces, i.e. emits light, after excitation under near-infrared light at $806 \mathrm{~nm}$ light. ICG is highly soluble in water and binds to $\beta$-lipoproteins, particularly to albumin. Because of the high protein content of lymph, ICG accumulates in the lymphatic pathways and lymph nodes. ICG-dyed lymph nodes become visible 5 minutes after light excitation and remain visible for around 60 minutes [10]. The intravascular halflife of ICG is 3-4 minutes; elimination occurs through the liver [11]. ICG has been approved for use in intravenous applications in the USA since 1956. Injection of ICG into tissue, for example in oncologic lymph node imaging, is an off-label use.

\section{Clinical application}

ICG is injected intraoperatively; it is easy to use logistically and does not increase surgical procedure times much [12]. In gynecological sentinel lymph node imaging ICG is injected into the uterine cervix, in rarer cases directly into the endometrium $[13,14]$. Intravenous applications of ICG are required in fluorescence angiography, video angiography and the imaging of liver tissue [1517]. The fluorescence of ICG is visualized using near-infrared light. A number of companies offer near-infrared cameras for open surgical, microscopic, laparoscopic and robot-assisted imaging of ICG, and a review article has compared the performance of these

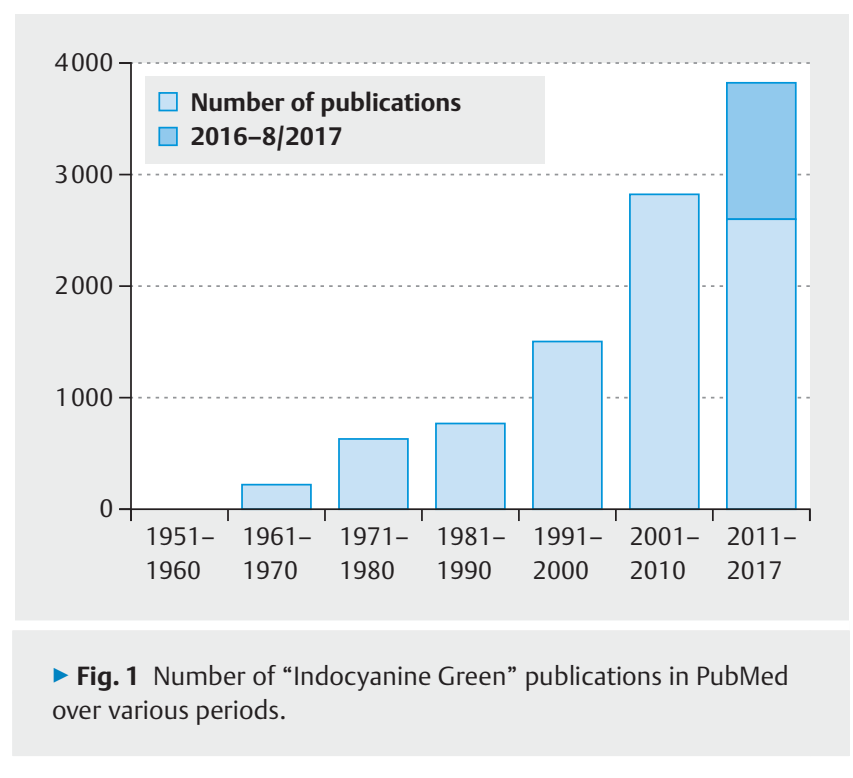

devices [18]. Modern imaging platforms are able to combine standard visible surgical images with fluorescence imaging under near-infrared light in real time ( $\triangleright$ Figs. 2 and 3 ). Color-coded quantified imaging of ICG makes it possible to differentiate between lymphatic pathways/lymph nodes and ICG fluorescence outside the lymphatic system ( $\bullet$ Fig. 2).

\section{Gynecology}

In modern oncology radical surgery should not consist of the undifferentiated removal of a large amount of tissue with its associated trauma. As clinical and scientific knowledge has expanded in the last few decades, the extent of radical surgery to treat breast cancer has continually decreased without reducing oncological safety [19]. The standard surgical procedure is now based on the sentinel lymph node concept, which has been scientifically verified at the highest level of evidence [19-21]. The sentinel lymph node concept has also found its way into guidelines on vulvar and cervical cancer and endometrial carcinomas (USA) and is the preferred approach for certain constellations of findings [22-24].

\section{The sentinel lymph node concept}

The rationale behind the sentinel lymph node concept is based on the observation that after peritumoral or interstitial injection of a 

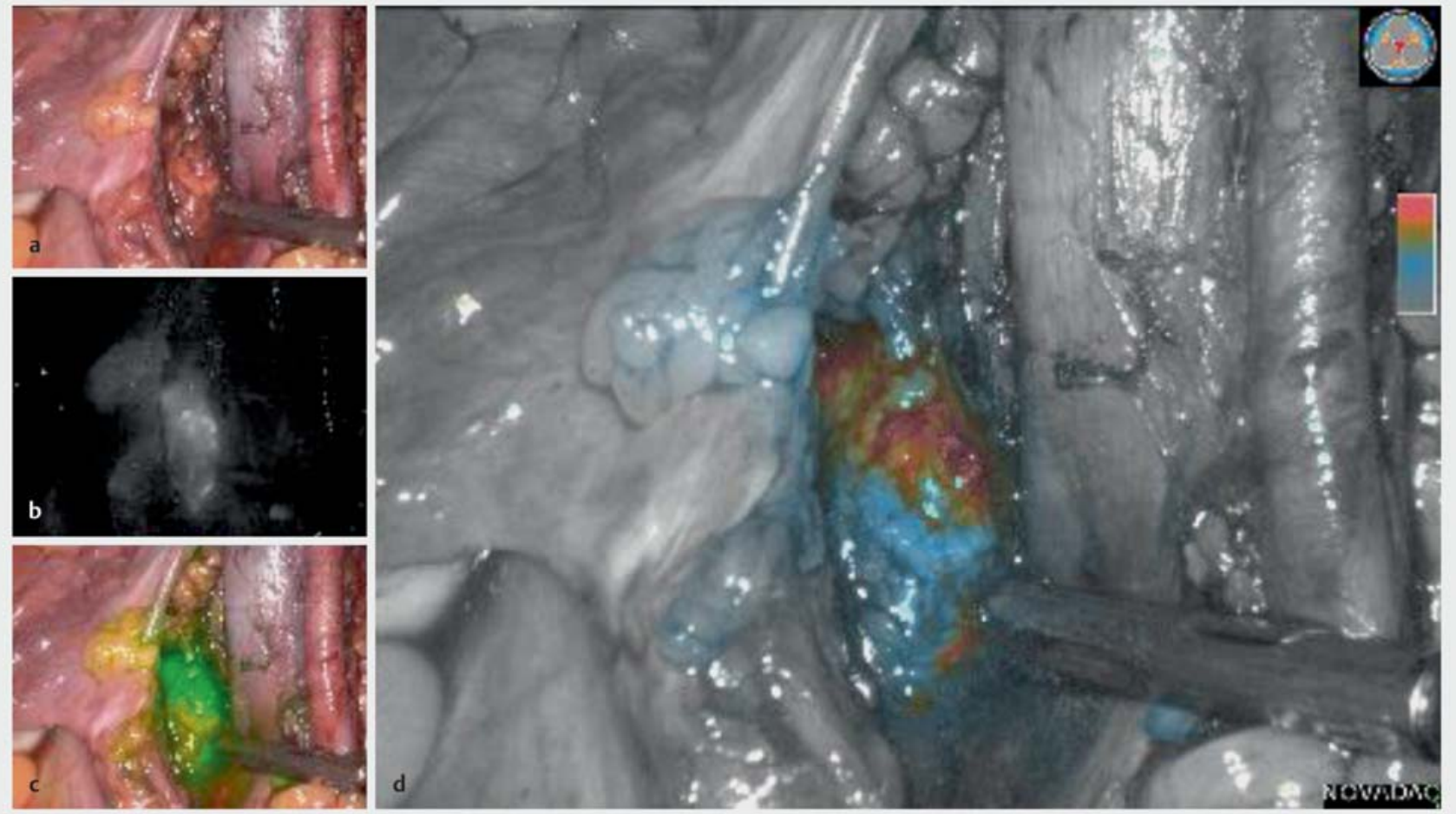

- Fig. 2 Intraoperative screen shot of fluorescence ICG sentinel lymph node biopsy in the right pelvis. a HD white light image of the site, b nearinfrared image at the same site with pale-stained ICG-containing tissue. c Combined HD image with fluorescent green color. $\mathbf{d}$ Quantitative ICG image of fluorescence-containing tissue indicating the presence of a lymph node in the obturator fossa.

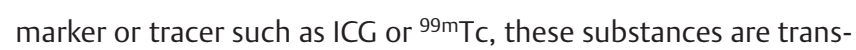
ported to the lymph nodes via the lymphatic pathways. The first lymph nodes to receive lymphatic drainage containing the tracer are referred to as the sentinel lymph nodes. Based on numerous studies, sentinel lymph nodes are considered to be representative for other lymph nodes in the same lymphatic drainage area; if the sentinel lymph node is tumor-free, radical lymphadenectomy is not required. This has led to a significant reduction in operating times and in the extent of surgical trauma and has reduced surgical and postoperative complications such as lymphedema or lymph cysts.

While axillary lymphatic drainage of breast cancer is almost always unilateral, matters are far more complicated with genital tumors, due to the possibility of unilateral, bilateral, superficial and deep dissemination [25].

Detection rates of more than $90 \%$ and, as a correlate for oncologic safety, a false-negative rate of not more than $5 \%$ are considered the threshold values for sentinel lymph node biopsies in breast cancer [26]. The detection rates for cervical cancer are around $80 \%$, with a bilateral detection rate for sentinel lymph nodes of between 50 and $61 \%$ [27].

Technetium colloid ${ }^{99 \mathrm{~m} T c}$ ) with and without simultaneous blue staining to improve detection rates and intraoperative gamma probe detection are used in many medical specialties $[20,28-$ 30]. All marking techniques have a learning curve for injection and detection [31,32]. A learning curve of 50 negative sentinel lymph nodes has been reported for sentinel lymph node visualization in axillary staging [33].

\section{Breast cancer}

The sentinel lymph node procedure has been used for more than 20 years in the primary surgical treatment of clinically node-negative breast cancer. Currently, the standard approach is a radioisotope procedure with technetium colloid $\left({ }^{99 \mathrm{~m} T c}\right)$. This requires the cooperation of gynecologists and nuclear medicine specialists. Marking the sentinel lymph node with Tc is usually done using a 2-day protocol and a dosage of 100-200 MBq and is checked preoperatively using lymph drainage scintigraphy. The use of scintigraphy is justified by existing regulations on radiation protection, although data is available which have shown that this verification is unnecessary for the surgical detection of lymph nodes [34]. The 2-day protocol and the logistics associated with nuclear medicine represent a hindrance in today's clinical care of breast cancer patients.

The use of ICG in axillary sentinel lymph node (SLN) biopsy was investigated quite early on [35]. Additional studies, the majority of which were done in Asia, have shown that a combination of ICG and blue dye is safe to use and highly sensitive. When both techniques were compared, ICG was found to have a higher rate of detection [1, 36 - 39]. Two recent publications in 2017 reported ICG detection rates of up to $100 \%$ in axillary SLN biopsy $[40,41]$. The use of ICG in breast cancer biopsies has also been investigated 

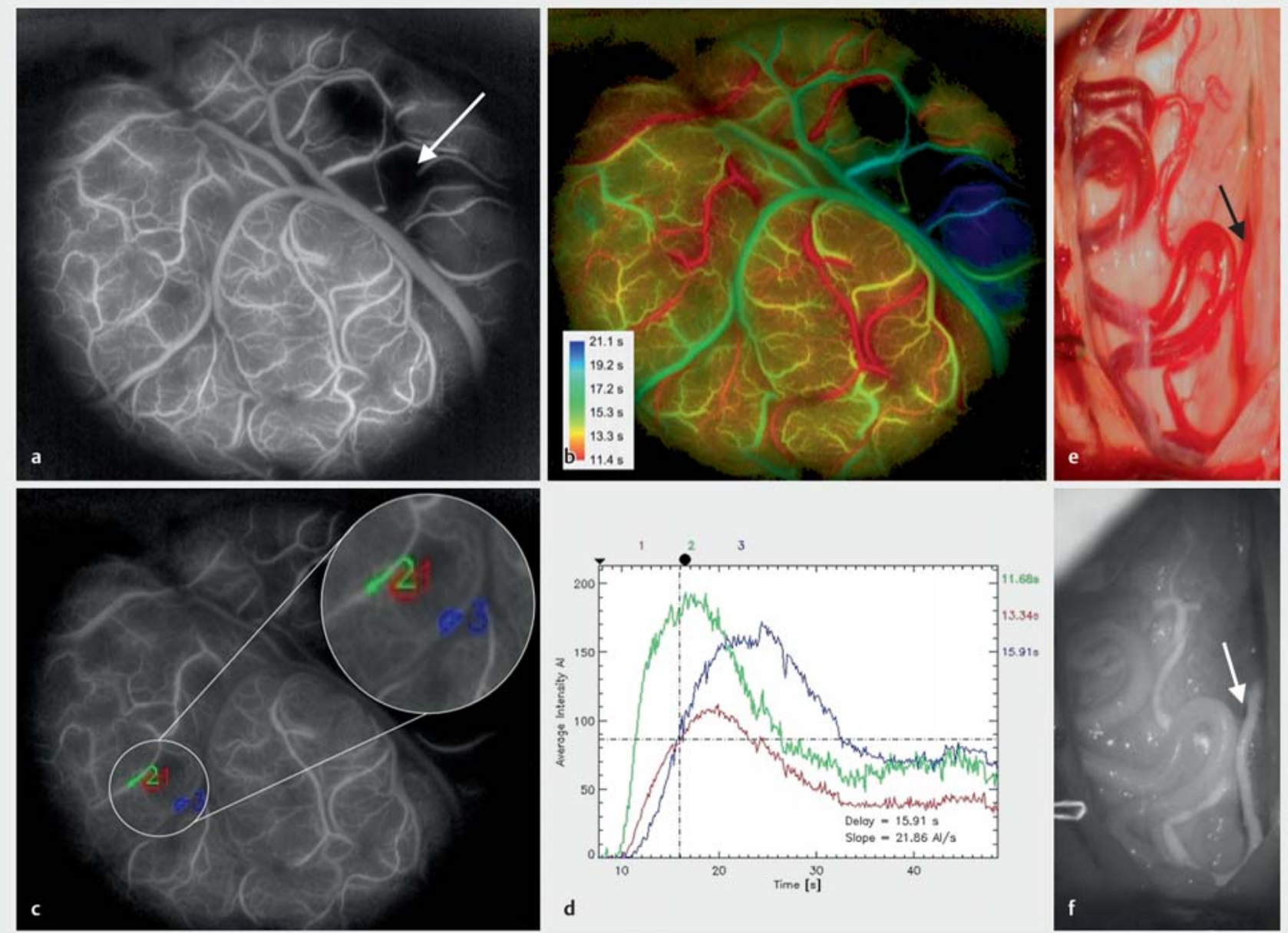

- Fig. 3 Applications in neurosurgery. a shows reduced flow at the cortical surface with circulatory insufficiency (white arrow). At maximum flow this is particularly visible in the color-coded image (b, blue areas). $\mathbf{c}$ shows how ROls (regions of interest) can be measured. Physicians can select an artery (green), vein (blue) or cortex (red). Areas of infarction or tumor areas can be highlighted. $\mathbf{d}$ shows the quantitative images for these regions. e Image of the spinal cord of a patient with a spinal arteriovenous fistula. Under white light illumination (black arrow), the suspicious vessel fills too quickly during ICG video angiography (f, white arrow), allowing it to be identified as a fistula vessel.

in Germany where it was found to be valid, feasible and with comparable results to those of methods using Tc; however, ICG was rated as more patient-friendly [42]. The administration of ICG prior to axillary surgery is simple: a periareolar intradermal injection is administered immediately before the start of surgery. Lymph nodes can already be detected a few minutes after the injection. The optimal concentration of ICG has been reported to be 3-6 $\mu \mathrm{g} /$ $\mathrm{ml}$ [43]. ICG administration is not associated with any cosmetically displeasing skin discoloration as occurs with the blue dye method. Elaborate logistics and expensive radiation protection measures as are required for Tc methods are unnecessary. The consumption costs of ICG are less than one quarter of those required for Tc technology, even excluding the additional time and personnel costs.

Two meta-analyses were published in 2016 and 2017 and evaluated 19 and 12 studies respectively, with around 2500 and 1700 patients. They reported that detection rates following ICG admin- istration in the axilla were $93-100 \%$, which is superior to some of the results obtained with technetium colloid techniques ( \pm blue) $[1,44]$.

In summary, there is extensive data and evidence showing that the ICG technique is well suited for axillary staging in breast cancer patients. The savings in terms of resources compared to Tc techniques is a significant advantage which - given the foreseeable developments in the clinical care of breast cancer patients and the trend towards very short in-hospital stays and outpatient treatment - militates for this new method.

\section{Cervical and endometrial carcinoma}

In their meta-analysis, Rusicto et al. reported that the results after using ICG for sentinel lymph node imaging in early cervical and endometrial carcinoma were equal to those obtained using the current standard of ${ }^{99 \mathrm{~m}} \mathrm{Tc}$ and blue dye [45]. Several recent publications found significantly better overall detection rates and bilat- 
- Table 1 Results of the current studies on sentinel lymph node imaging with blue dye, technetium + blue dye and indocyanine green in cervical and endometrial carcinoma, which were published after the meta-analysis by Ruscito et al. in 2016 [45]. Data from the meta-analysis by Lin and colleagues [3] on endometrial carcinoma are also included.

\begin{tabular}{|c|c|c|c|c|c|}
\hline Publication & Entity & Parameter & Blue dye & $\begin{array}{l}\text { Technetium + } \\
\text { Blue dye }\end{array}$ & $\begin{array}{l}\text { Indocyanine } \\
\text { green }\end{array}$ \\
\hline \multirow{2}{*}{$\begin{array}{l}\text { Eriksson et al. } 2017 \text { [46] } \\
n=472\end{array}$} & \multirow{2}{*}{$\begin{array}{l}\text { Cervical cancer and en- } \\
\text { dometrial carcinoma }\end{array}$} & Rate of detection & $81 \%$ & - & $95 \%$ \\
\hline & & Bilateral rate of detection & $54 \%$ & - & $85 \%$ \\
\hline \multirow{2}{*}{$\begin{array}{l}\text { Beavis et al. } 2016 \text { [47] } \\
\mathrm{n}=30\end{array}$} & \multirow[t]{2}{*}{ Cervical cancer } & Rate of detection & - & - & $100 \%$ \\
\hline & & Bilateral rate of detection & - & - & $87 \%$ \\
\hline \multirow{2}{*}{$\begin{array}{l}\text { Buda et al. } 2016 \text { [2] } \\
n=144\end{array}$} & & Rate of detection & - & $95 \%$ & $100 \%$ \\
\hline & & Bilateral rate of detection & - & $76.3 \%$ & $98.5 \%$ \\
\hline \multirow{2}{*}{$\begin{array}{l}\text { Lin et al. } 2017 \text { [3] } \\
\mathrm{n}=2236\end{array}$} & \multirow[t]{2}{*}{ Endometrial carcinoma } & Rate of detection & $76 \%(71-81 \%)$ & $86 \%(82-90 \%)$ & $93 \%(89-96 \%)$ \\
\hline & & Sensitivity & $90 \%(79-96 \%)$ & $92 \%(84-96 \%)$ & $87 \%(76-93 \%)$ \\
\hline
\end{tabular}

eral rates of detection when ICG was used compared to conventional procedures ( $\triangleright$ Table 1$)[2,46,47]$.

The most recent data from a prospective, multicenter cohort study which compared the outcomes after removal of sentinel lymph nodes and complete lymphadenectomy in endometrial carcinoma (FIRES trial) showed a high sensitivity of $97.2 \%$ and a negative predictive value of $99.6 \%$ for the accurate detection of lymph node metastases in endometrial carcinoma [48]. In their highly regarded Lancet Oncology article, Rossi et al. concluded that sentinel lymph node biopsy can be used safely to replace diagnostic (staging) lymphadenectomy procedures [48].

\section{Visceral Surgery}

ICG is used in visceral surgery for the objective measurement of blood flow in colorectal anastomosis. Other areas of application are based on the elimination of ICG through the liver and biliary ducts. ICG is used in cholangiography and for the detection of subcapsular liver tumors. In biliary excretion disorders, ICG accumulates in hepatocellular carcinomas and around metastases of adenocarcinomas in non-cancerous liver tissue.

A new area of application which is still in its experimental stages is the use of ICG to detect peritoneal tumor foci of colorectal cancers. Recent studies have shown that detection during cytoreductive procedures is possible, and in almost one third of cases, this led to a change in the planned procedure $[49,50]$.

\section{ICG fluorescence angiography for colorectal anastomosis}

Insufficient perfusion of an anastomosis after colorectal resection, also known as anastomotic insufficiency (AI), is a serious complication with significant rates of morbidity and mortality. The incidence of anastomotic insufficiency is between 3 and 19\%. Deep anterior rectal resections are particularly associated with high rates of anastomotic insufficiency [51,52]. Although risk factors for $\mathrm{Al}$ are multifactorial, impaired perfusion plays a central role $[52,53]$.

Often only subjective clinical tests are available for the intraoperative evaluation of perfusion. The color of the intestinal wall, the extent of peristalsis, the pulse of the arterial arcades supplying the area, and mucosal bleeding are used to estimate perfusion [54]. ICG fluorescence angiography has emerged as the most promising technology for the objective measurement of perfusion. In several case series, the use of ICG led to a change in the planned point of transection in the intestine in up to $19 \%$ of cases, reducing the subsequent rate of anastomotic insufficiency [5557]. A prospective, multicenter study (PILLAR II) found that the use of fluorescence imaging led to a revision of the planned resection site in $8 \%$ of cases; the final insufficiency rate was $1.4 \%$ [58]. In a review of published clinical studies which looked at a total of 916 patients, the $\mathrm{Al}$ risk in the fluorescence group was 3.3\% compared to a rate of $8.5 \%$ in the group without ICG fluorescence measurement [59]. Another review article found that the use of ICG fluorescence resulted in a change of surgical procedures in 11 of 16 studies. In two of the studies, the rate of anastomotic leakage was reduced by 4 and $11 \%$, respectively. Only one of the studies reported no improvement in the $\mathrm{Al}$ rate in the fluorescence group [60].

In summary, the use of ICG fluorescence angiography in colorectal surgery is feasible and useful, although controlled randomized studies are still lacking.

\section{ICG in hepatobiliary surgery}

ICG has been used in hepatic function examinations for more than 20 years. Imaging tissue structures has only become relevant in recent years. The first fluorescent cholangiography was described in 2009 [61]. Other studies have reported an accumulation of ICG in hepatocellular carcinoma and multifocal adenocarcinoma [62, 63]. Improvements in imaging have led to the visualization of hepatic segment borders, allowing anatomical resections to become more precise $[16,64,65]$. ICG fluorescence angiography has been used after split liver transplantations to evaluate vascular reconstruction [66].

As the number of robot-assisted, minimally invasive surgical procedures in hepatobiliary surgery increases, the first series on laparoscopic robotic cholecystectomies with ICG fluorescent cholangiography have been published $[67,68]$. One study showed a 

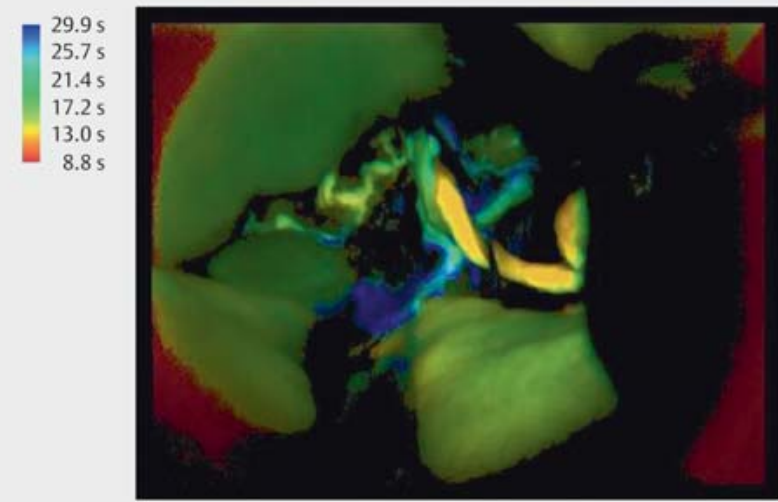

- Fig. 4 Color-coded imaging $\left(\right.$ FLOW $\left.^{\circledR} 800\right)$ of the afferent (yelloworange) artery and the efferent vein (green) of a microvascular, latissimus dorsi tissue flap after successful anastomosis.

reduction in complication and conversion rates compared to laparoscopic resection [68].

The accumulation of ICG in hepatic focal lesions could be useful in minimally invasive liver resection where palpation of the finding is not possible. The detection depth is only $5-10 \mathrm{~mm}$ and a number of false positive and negative findings have been reported, so that a final assessment of the benefit of ICG fluorescence imaging cannot yet be made here $[16,66]$.

\section{Plastic Surgery}

\section{Intraoperative ICG angiography}

There are numerous procedures in plastic reconstructive surgery which can be used to monitor the tissue transplants, and each method has its own limitations and advantages [69,70]. Apart from the purely clinical examination, there is no established standard yet. Two different aspects can be investigated with ICG angiography. ICG angiography can be used to make a valid assessment of the vascular anastomosis and its patency $[71,72]$, and it can also be used to make predictions about the perfusion of the transplanted tissue $[73,74]$. While this technology was described quite early on [63], it was initially not introduced into standard clinical practice for the perioperative evaluation of the perfusion of tissue transplants. The use of ICG for objective evaluations of perfusion requires surgical microscopes and special software [74-76]. The use of ICG to interpret findings is based on direct, quantitative, real-time flow measurements which show perfusion as visual images which can be used to evaluate both anastomoses and tissue transplants in the immediate and vulnerable postoperative phase.

There are a range external programs for the analysis of images, including the IC-VIEW, the IC-CALC (Pulsion Medical Systems AG, Munich, Germany), the SPY 2001 Imaging System (Novadaq, Bonita Springs, FL, USA) and the SPY Elite ${ }^{\circledR}$ System (LifeCell Corp., Branchburg, NJ, USA). The FLOW ${ }^{\circledR} 800$ tool (FLOW 800; Carl Zeiss AG, Oberkochen, Germany) is a special case as it is integrated in the surgical microscope which is useful for intraoperative use and analysis. It can be used for flow analysis as it calculates emitted fluorescence signals and can create color coding based on fluorescence intensity ( $\triangleright$ Fig. 4) [74-78]. This ability to evaluate microanastomoses and tissue transplants intraoperatively has made the intraoperative assessment of flap plasties significantly easier and has improved success rates [79-81]. Perfusion can be validly evaluated by using the analyzed data to detect anastomotic complications or inadequate tissue perfusion in border areas during the postoperative period $[74,75,80,82-84]$.

\section{Neurosurgery}

Video angiography was introduced at the start of the millennium. In its current form where fluorescence video angiography is integrated in the surgical microscope, it is indispensable in modern neurosurgical operating rooms $[85,86]$.

\section{Vascular neurosurgery}

In vascular neurosurgery, ICG is primarily used to visualize vascular pathologies (angiomas, aneurysms) and their origins, to differentiate these lesions from adjacent vessels which are not part of the pathology, to show transfers from venous to arterial circulation (fistulas) and, above all, to monitor treatment success intraoperatively after eliminating fistulas or aneurysms.

ICG video angiography is used in cerebral cavernoma surgery and the surgery of arteriovenous malformations (AVM), dural arteriovenous fistulas (dAVF) [87] and aneurysms [88], and to treat spinal vascular pathologies ([89], > Fig. 3 e and f). In more than $90 \%$ of cases, the results of ICG video angiography corresponded to those obtained by digital subtraction angiography, currently the gold standard for the imaging of vascular anomalies [88]. Hybrid surgery with angiography or intraoperative cross-sectional imaging is currently needed to carry out subtraction angiography intraoperatively. The use of these additional techniques significantly increases operating times, which is why they have been largely abandoned in favor of ICG.

Further improvements in video angiography include colorcoded and (semi-)quantitative video angiography ( $\bullet$ Fig. $3 \mathrm{c}$ and d), which provides even more information about regional perfusion.

\section{Cerebral tumor surgery}

As evaluating vascular conditions around malignancies is also very important in cerebral tumor surgery, ICG video angiography can offer certain advantages. Intraoperative vascular imaging is particularly useful to evaluate transit feeders and draining veins during the resection of malignancies [90].

\section{Evaluation of cerebral trauma}

A very recently published article reported on the use of quantitative ICG video angiography to determine blood flow parameters in the cerebral vessels during decompressive craniectomy for traumatic brain injury. A clear correlation between cranial pressure and clinical outcome was recorded after 3 months. It is probable that ICG video angiography will be useful to assess prognosis in future [91]. 


\section{Conclusion}

Using ICG in medicine is simple, radiation-free and safe, and ICG has been shown to be an excellent marker after both interstitial and intravascular administration. The detection rates of ICG-dyed sentinel lymph nodes are at least as good as those reported for established techniques and sometimes even superior. Moreover, using ICG to detect sentinel lymph nodes is less expensive and logistically simpler than protocols which use technetium colloid ( $\left.{ }^{99 m} \mathrm{Tc}\right)$ the day before surgery, when it is administered by nuclear medicine specialists in accordance with radiation protection regulations [19,20].

ICG has been used in medicine for more than fifty years, and side effects are very rare. After a total of 240000 ICG administrations, Garski et al. reported only four intolerance reactions [92].

Although intravascular ICG injection has been approved since the 1950s and is used in standard clinical practice, interstitial injection of ICG is still off-label.

The limitations of ICG video angiography are its low penetration depth, which means that only superficial processes can be evaluated, and the fact that an interval of several minutes is necessary between two video angiographies to allow the initially injected ICG to flow out of the venous and arterial system again. The scientific data on the use of ICG are excellent. However, further prospective randomized studies will be necessary to establish this method in routine clinical practice.

\section{Acknowledgements}

The authors would like to thank Prof. Dr. Dr. Ralf Smeets for his expertise and review of the manuscript.

\section{Conflict of Interest}

AH: Perform live surgery and participation in expert meetings for Olympus.

\section{References}

[1] Sugie T, Ikeda T, Kawaguchi A et al. Sentinel lymph node biopsy using indocyanine green fluorescence in early-stage breast cancer: a metaanalysis. Int J Clin Oncol 2017; 22: 11-17

[2] Buda A, Papadia A, Zapardiel I et al. From conventional radiotracer Tc-99 (m) with blue dye to indocyanine green fluorescence: a comparison of methods towards optimization of sentinel lymph node mapping in early stage cervical cancer for a laparoscopic approach. Ann Surg Oncol 2016; 23: 2959-2965

[3] Lin H, Ding Z, Kota VG et al. Sentinel lymph node mapping in endometrial cancer: a systematic review and meta-analysis. Oncotarget 2017; 8: 46601-46610

[4] Rocha A, Domínguez AM, Lécuru F et al. Indocyanine green and infrared fluorescence in detection of sentinel lymph nodes in endometrial and cervical cancer staging - a systematic review. Eur J Obstet Gynecol Reprod Biol 2016; 206: 213-219

[5] Handgraaf HJM, Boogerd LSF, Höppener DJ et al. Long-term follow-up after near-infrared fluorescence-guided resection of colorectal liver metastases: a retrospective multicenter analysis. Eur J Surg Oncol 2017; 43: 1463-1471
[6] Tanaka K, Mori R, Kawamura A et al. Comparison of OCT angiography and indocyanine green angiographic findings with subtypes of polypoidal choroidal vasculopathy. Br J Ophthalmol 2017; 101: 51-55

[7] Senders JT, Muskens IS, Schnoor R. Agents for fluorescence-guided glioma surgery: a systematic review of preclinical and clinical results. Acta Neurochir 2017; 159: 151-167

[8] Burnier P, Niddam J, Bosc R et al. Indocyanine green applications in plastic surgery: a review of the literature. Plast Reconstr Aesthet Surg 2017; 70: $814-827$

[9] Wheeler HO, Cranston WI, Meltzer JI. Hepatic uptake and biliary excretion of indocyanine green in the dog. Proc Soc Exp Biol Med 1958; 99: $11-14$

[10] Choi HJ, Kim T], Lee YY et al. Time-lapse imaging of sentinel lymph node using indocyanine green with near-infrared fluorescence imaging in early endometrial cancer. J Gynecol Oncol 2016; 27: e27

[11] Cherrick GR, Stein SW, Leevy CM et al. Indocyanine green: observations on its physical properties, plasma decay, and hepatic extraction. J Clin Invest 1960; 39: 592-600

[12] Darin MC, Gomez-Hidalgo NR, Westin SN et al. Role of indocyanine green in sentinel node mapping in gynecologic cancer: is fluorescence imaging the new standard? J Minim Invasive Gynecol 2016; 23: 186-193

[13] Levinson K, Mahdi H, Escobar P. Feasibility and optimal dosage of indocyanine green fluorescence for sentinel lymph node detections using robotic single site instrumentation: preclinical study. J Minim Invasive Gynecol 2013; 12: 211-215

[14] Martinelli F, Ditto A, Signorelli M et al. Sentinel node mapping in endometrial cancer following hysteroscopic injection of tracers: a single center evaluation over 200 cases. Gynecol Oncol 2017; 146: 525-530

[15] Ris F, Hompes R, Cunningham C et al. Near-infrared (NIR) perfusion angiography in minimally invasive colorectal surgery. Surg Endosc 2014; 28: $2221-2226$

[16] Zhang YM, Shi R, Hou JC et al. Liver tumor boundaries identified intraoperatively using real-time indocyanine green fluorescence imaging. J Cancer Res Clin Oncol 2017; 143: 51-58

[17] Boogerd LSF, Handgraaf HJM, Huurman VAL et al. The best approach for laparoscopic fluorescence cholangiography: overview of the literature and optimization of dose and dosing time. Surg Innov 2017; 24: 386396

[18] Zhu B, Sevick-Muraca EM. A review of performance of near-infrared fluorescence imaging devices used in clinical studies. Br ] Radiol 2015; 88: 20140547

[19] Janni W, Kühn T, Schwentner L et al. Sentinel node biopsy and axillary dissection in breast cancer-the evidence and its limits. Dtsch Arztebl Int 2014; 111: 244-249

[20] AWMF. AWMF Leitlinie Mammakarzinom. Online: http://www.awmf. org/uploads/tx_szleitlinien/032-045OL_k_S3_Brustkrebs_ Mammakarzinom_Diagnostik_Therapie_Nachsorge_2012-07.pdf; last access: 20.05.2017

[21] Krag DN, Anderson SJ, Julian TB et al. Sentinel-lymph-node resection compared with conventional axillary-lymph-node dissection in clinically node-negative patients with breast cancer: overall survival findings from the NSABP B-32 randomised phase 3 trial. Lancet Oncol 2010; 11: 927933

[22] AWMF. AWMF Leitlinien Zervixkarzinom. Online: http://www.awmf.org/ uploads/tx_szleitlinien/032-033OLk_S3_Zervixkarzinom_2014-10.pdf; last access: 30.01.2017

[23] AWMF. AWMF Leitlinien Vulvakarzinom. Online: http://www.awmf.org/ uploads/tx_szleitlinien/015-059k_s2k_Vulvakarzinom_und_Vorstufen_ Diagnostik_Therapie_2016-11.pdf; last access: 30.01.2017

[24] NCCN. NCCN guideline. Online: https://www.tri-kobe.org/nccn/ guideline/gynecological/english/uterine.pdf; last access: 18.08.2017 
[25] van der Zee AG], Oonk MH, De Hullu JA et al. Sentinel node dissection is safe in the treatment of early-stage vulvar cancer. J Clin Oncol 2008; 26 : 884-889

[26] Schrenk P, Shamiyeh A, Wayand W. Sentinel lymph-node biopsy compared to axillary lymph-node dissection for axillary staging in breast cancer patients. Eur J Surg Oncol 2001; 27: 378-382

[27] van de Lande J et al. Sentinel lymph node detection in early stage uterine cervix carcinoma: a systematic review. Gynecol Oncol 2007; 106: 604613

[28] Krag DN, Meijer S], Weaver DL et al. Minimal-access surgery for staging of malignant melanoma. Arch Surg 1995; 130: 654-658

[29] Tafra L, Lannin DR, Swanson MS. Multicenter trial of sentinel node biopsy for breast cancer using both technetium sulphur colloid and isosulfan blue dye. Ann Surg 2001; 233: 51-59

[30] Lee JH, Ryu KW, Kook MC et al. Feasibility of laparoscopic sentinel basin dissection for limited resection in early gastric cancer. J Surg Oncol 2008; 98: $331-335$

[31] Buda A, Crivellaro C, Elisei F et al. Impact of indocyanine green for sentinel lymph node mapping in early stage endometrial and cervical cancer: comparison with conventional radiotracer $(99 \mathrm{~m})$ Tc and/or blue dye. Ann Surg Oncol 2016; 23: 2183-2191

[32] Wuntakal R, Papadopoulos AJ, Montalto SA et al. Location of sentinel lymph node in cervical carcinoma and factors associated with unilateral detection. Int J Gynecol Cancer 2015; 25: 1663-1668

[33] Haid A, Köberle-Wührer R, Offner F et al. Klinische Wertigkeit und zukünftige Aspekte der „Sentinel Node Biopsy“ beim Mammakarzinom. Chirurg 2003; 74: 657-664

[34] Kümmel S, Holtschmidt ], Gerber B et al. Randomized surgical multicenter trial to evaluate the usefulness of lymphoscintigraphy (LSG) prior to sentinel node biopsy (SLNB) in early breast cancer: SenSzi (GBG80) trial. J Clin Oncol 2017; 35 (15 Suppl.): 555

[35] Motomura K, Inaji H, Komoike $\mathrm{Y}$ et al. Sentinel node biopsy guided by indocyanine green dye in breast cancer patients. Jpn J Clin Oncol 1999; 29: 604-607

[36] Hojo T, Nagao T, Kikuyama M et al. Evaluation of sentinel node biopsy by combined fluorescent and dye method and lymph flow for breast cancer. Breast 2010; 19: 210-213

[37] Sugie T, Sawada T, Tagaya $\mathrm{N}$ et al. Comparison of the indocyanine green fluorescence and blue dye methods in detection of sentinel lymph nodes in early-stage breast cancer. Ann Surg Oncol 2013; 20: 2213-2218

[38] Kitai T, Inomoto T, Miwa M et al. Fluorescence navigation with indocyanine green for detecting sentinel lymph nodes in breast cancer. Breast Cancer 2005; 12: 211-215

[39] Pitsinis V, Provenzano E, Kaklamis L et al. Indocyanine green fluorescence mapping for sentinel lymph node biopsy in early breast cancer. Surg Oncol 2015; 24: 375-379

[40] Liu J, Huang L, Wang $N$ et al. Indocyanine green detects sentinel lymph nodes in early breast cancer. J Intern Med Res 2017; 45: 514-524

[41] Ji Y, Luo N, Jiang Y et al. Clinical utility of the additional use of blue dye for indocyanine green for sentinel biopsy in breast cancer. J Surg Res 2017; 215: 88-92

[42] Grischke EM, Röhm C, Hahn M et al. ICG fluorescence technique for the detection of sentinel lymph nodes in breast cancer: results of a prospective open-label clinical trial. Geburtsh Frauenheilk 2015; 75: 935-940

[43] Paik HJ, Yi HW, Park S et al. Optimal concentration of indocyanine green in near-infrared fluorescence guided sentinel lymph node biopsy in breast cancer. Cancer Res 2016; Abstr. P3-01-03

[44] Zhang X, Li Y, Zhou Y et al. Diagnostic performance of indocyanine green-guided sentinel lymph node biopsy in breast cancer: a meta-analysis. PLoS 2016; 11: e0155597
[45] Ruscito I, Gasparri ML, Braicu El et al. Sentinel node mapping in cervical and endometrial cancer: indocyanine green versus other conventional dyes - a meta-analysis. Ann Surg Oncol 2016; 23: 3749-3756

[46] Eriksson AG, Beavis A, Soslow RA et al. A comparison of the detection of sentinel lymph nodes using indocyanine green and near-infrared fluorescence imaging versus blue dye during robotic surgery in uterine cancer. Int J Gynecol Cancer 2017; 27: 743-747

[47] Beavis AL, Salazar-Marioni S, Sinno AK et al. Sentinel lymph node detection rates using indocyanine green in women with early-stage cervical cancer. Gynecol Oncol 2016; 143: 302-306

[48] Rossi EC, Kowalski LD, Scalici J et al. A comparison of sentinel lymph node biopsy to lymphadenectomy for endometrial cancer staging (FIRES trial): a multicentre, prospective, cohort study. Lancet Oncol 2017; 18: $384-$ 392

[49] Filippello A, Porcheron J, Klein JP et al. Affinity of indocyanine green in the detection of colorectal peritoneal carcinomatosis. Surg Innov 2017; 24: 103-108

[50] Liberale G, Vankerckhove S, Caldon MG et al. Fluorescence imaging after indocyanine green injection for detection of peritoneal metastases in patients undergoing cytoreductive surgery for peritoneal carcinomatosis from colorectal cancer: a pilot study. Ann Surg 2016; 264: 1110-1115

[51] Branagan G, Finnis D; Wessex Colorectal Cancer Audit Working Group. Prognosis after anastomotic leakage in colorectal surgery. Dis Colon Rectum 2005; 48: 1021-1026

[52] Kingham TP, Pachter HL. Colonic anastomotic leak: risk factors, diagnosis and treatment. J Am Coll Surg 2009; 208: 269-278

[53] Vignali A, Gianotti L, Braga M et al. Altered microperfusion at the rectal stump is predictive for rectal anastomotic leak. Dis Colon Rectum 2000; 43: $76-82$

[54] Karliczek A, Harlaar N], Zeebregts C] et al. Surgeons lack predictive accuracy for anastomotic leakage in gastrointestinal surgery. Int J Colorectal Dis 2009; 24: 569-576

[55] Kudszus S, Roesel C, Schachtrupp A et al. Intraoperative laser fluorescence angiography in colorectal surgery: a noninvasive analysis to reduce the rate of anastomotic leakage. Langenbecks Arch Surg 2010; 395: $1025-1030$

[56] Jafari MD, Lee KH, Halabi W] et al. The use of indocyanine green fluores cence to assess anastomotic perfusion during robotic assisted laparoscopic rectal surgery. Surg Endosc 2013; 27: 3003-3008

[57] Kawada K, Hasegawa S, Wada T. Evaluation of intestinal perfusion by ICG fluorescence imaging in laparoscopic colorectal surgery with DST anastomosis. Surg Endosc 2017; 31: 1061-1069

[58] Jafari MD, Wexner SD, Martz JE et al. Perfusion assessment in laparoscopic left sided/anterior resection (PILLAR II): a multi-institutional study. J Am Coll Surg 2015; 220: 82-92

[59] Degett TH, Andersen HS, Gögenur I. Indocyanine green fluorescence angiography for intraoperative assessment of gastrointestinal anastomotic perfusion: a systematic review of clinical trials. Langenbecks Arch Surg 2016; 401: 767-775

[60] Mizrahi I, Wexner SD. Clinical role of fluorescence imaging in colorecta surgery - a review. Expert Rev Med Devices 2017; 14: 75-82

[61] Ishizawa T, Bandai Y, Kokudo N. Fluorescent cholangiography using indocyanine green for laparoscopic cholecystectomy: an initial experience. Arch Surg 2009; 144: 381-382

[62] Ishizawa T, Fukushima N, Shibahara J et al. Real-time identification of liver cancers by using indocyanin green fluorescent imaging. Cancer 2009; 115: 2491-2504

[63] Ishizawa T, Masuda K, Urano Y et al. Mechanistic background and clinical applications of indocyanine green fluorescence imaging of hepatocellular carcinoma. Ann Surg Oncol 2014; 21: 440-448

[64] Inoue Y, Arita J, Sakamoto T et al. Anatomical liver resections guided by 3-dimensional parenchymal staining using fusion indocyanine green fluorescence imaging. Ann Surg 2015; 262: 105-111 
[65] Miyata A, Ishizawa T, Tani K et al. Reappraisal of a dye-staining technique for anatomic hepatectomy by the concomitant use of indocyanine green fluorescence imaging. J Am Coll Surg 2015; 221: e27-e36

[66] Majlesara A, Golriz M, Hafezi M et al. Indocyanine green fluorescence imaging in hepatobiliary surgery. Photodiagnosis Photodyn Ther 2017. doi:10.1016/j.pdpdt.2016.12.005

[67] Daskalaki D, Fernandes E, Wang X et al. Indocyanine green (ICG) fluorescent cholangiography during robotic cholecystectomy: results of 184 consecutive cases in a single institution. Surg Innov 2014; 21: 615-621

[68] Gangemi A, Danilkowicz R, Elli FE et al. Could ICG-aided robotic cholecystectomy reduce the rate of open conversion reported with laparoscopic approach? A head to head comparison of the largest single institution studies. J Robot Surg 2017; 11: 77-82

[69] Abdel-Galil K, Mitchell D. Postoperative monitoring of microsurgical free-tissue transfers for head and neck reconstruction: a systematic review of current techniques-part II. Invasive techniques. $\mathrm{Br}$ J Oral Maxillofac Surg 2009; 47: 438-442

[70] Abdel-Galil K, Mitchell D. Postoperative monitoring of microsurgical free-tissue transfers for head and neck reconstruction: a systematic review of current techniques-part I. Non-invasive techniques. $\mathrm{Br} J$ Oral Maxillofac Surg 2009; 47: 351-355

[71] Holm C, Mayr M, Hofter E et al. Assessment of the patency of microvascular anastomoses using microscope-integrated near-infrared angiography: a preliminary study. Microsurgery 2009; 29: 509-514

[72] Mücke T, Wolff KD, Wagenpfeil S et al. Reliability of near-infrared angiography and micro-Doppler sonography for evaluating microvascular anastomoses. Plast Reconstr Surg 2010; 126: 1506-1514

[73] Holzbach T, Taskov C, Henke ] et al. [Evaluation of perfusion in skin flaps by laser-induced indocyanine green fluorescence]. Handchir Mikrochir Plast Chir 2005; 37: 396-402

[74] Mücke T, Fichter AM, Schmidt LH et al. Indocyanine green videoangiography-assisted prediction of flap necrosis in the rat epigastric flap using the flow ${ }^{\circledR} 800$ tool. Microsurgery 2017; 37: 235-242

[75] Mücke T, Reeps C, Wolff KD et al. Objective qualitative and quantitative assessment of blood flow with near-infrared angiography in microvascular anastomoses in the rat model. Microsurgery 2013; 33: 287-296

[76] Mücke T, Wolff KD, Wagenpfeil S et al. Reliability of near-infrared angiography and micro-Doppler sonography for evaluating microvascular anastomoses. Plast Reconstr Surg 2010; 126: 1506-1514

[77] Detter C, Wipper S, Russ D et al. Fluorescent cardiac imaging: a novel intraoperative method for quantitative assessment of myocardial perfusion during graded coronary artery stenosis. Circulation 2007; 116: 1007-1014
[78] Kamp MA, Slotty P, Turowski B et al. Microscope-integrated quantitative analysis of intraoperative indocyanine green fluorescence angiography for blood flow assessment: first experience in 30 patients. Neurosurgery 2012. doi:10.1227/NEU.0b013e31822f7d7c

[79] Holm C, Dornseifer U, Sturtz G et al. The intrinsic transit time of free microvascular flaps: clinical and prognostic implications. Microsurgery 2010; 30: 91-96

[80] Holm C, Mayr M, Hofter E et al. Assessment of the patency of microvascular anastomoses using microscope-integrated near-infrared angiography: a preliminary study. Microsurgery 2009; 29: 509-514

[81] Waseda K, Ako J, Hasegawa T et al. Intraoperative fluorescence imaging system for on-site assessment of off-pump coronary artery bypass graft. JACC Cardiovasc Imaging 2009; 2: 604-612

[82] Holm C, Dornseifer U, Sturtz G et al. Sensitivity and specificity of ICG angiography in free flap reexploration. J Reconstr Microsurg 2010; 26: 311-316

[83] Holzbach T, Artunian N, Spanholtz TA et al. [Microscope-integrated intraoperative indocyanine green angiography in plastic surgery]. Handchir Mikrochir Plast Chir 2012; 44: 84-88

[84] Zimmermann A, Roenneberg C, Wendorff $\mathrm{H}$ et al. Early postoperative detection of tissue necrosis in amputation stumps with indocyanine green fluorescence angiography. Vasc Endovascular Surg 2010; 44: 269-273

[85] Chiang VL, Gailloud P, Murphy KJ et al. Routine intraoperative angiography during aneurysm surgery. J Neurosurg 2002; 96: 988-992

[86] Raabe A, Beck J, Gerlach R et al. Near-infrared indocyanine green video angiography: a new method for intraoperative assessment of vascular flow. Neurosurgery 2003; 52: 132-139

[87] Hänggi D, Etminan N, Steiger HJ. The impact of microscope-integrated intraoperative near-infrared indocyanine green videoangiography on surgery of arteriovenous malformations and dural arteriovenous fistulae. Neurosurgery 2003; 67: 1094-1103

[88] Raabe A, Nakaji P, Beck J et al. Prospective evaluation of surgical microscope-integrated intraoperative near-infrared indocyanine green videoangiography during aneurysm surgery. J Neurosurg 2005; 103: 982-989

[89] Takai K, Kurita H, Hara T et al. Influence of indocyanine green angiography on microsurgical treatment of spinal perimedullary arteriovenous fistulas. Neurosurg Focus 2016; 40: E10

[90] Murai Y, Adachi K, Matano F et al. Indocyanin green videoangiography study of hemangioblastomas. Can J Neurol Sci 2011; 38: 41-47

[91] Kamp MA, Sarikaya-Seiwert S, Petridis AK et al. Intraoperative indocyanine green-based cortical perfusion assessment in patients suffering from severe traumatic brain injury. World Neurosurg 2017; 101: 431443

[92] Garski TR, Staller B], Hepner G et al. Adverse reactions after administration of indocyanine green. JAMA 1978; 240: 635 